\title{
EVIDENCE REVIEW: ACHIEVING COVID-19 VACCINE EQUITY IN EALING AND NORTH WEST LONDON
}

Social Science in Humanitarian Action Platform

This review sets out key considerations for improving vaccine equity - as well as broader health equity - in the North West London (NWL) borough of Ealing. It foregrounds the political, economic and social dynamics which have perpetuated health inequalities during and prior to COVID-19, and how they have manifested to shape unequal COVID-19 vaccine accessibility and uptake among different social groups. It also highlights how local actors have sought to address these inequalities. By bringing together data and insights from existing social science research and consultations with people involved in local COVID-19 vaccination efforts (in local authorities, the NHS and community groups), we point to ways local authorities and healthcare providers, in collaboration with local people and organisations, can support vaccine equity - and health equity more broadly - now, and into the future. Critical to this are further efforts to integrate sensitivity to context, sustain collaborative working, build trust and meaningfully engage citizens (especially vulnerable groups), and support a robust civil society. The review begins with summary key considerations for operational actors. This review was produced by SSHAP in collaboration with Ealing Council. It was authored by Tabitha Hrynick and Santiago Ripoll, and reviewed by Maddy Gupta-Wright, Ellen Schwartz, and Nikita Simpson. It is the responsibility of SSHAP. ${ }^{\mathrm{i}}$

\section{SUMMARY CONSIDERATIONS}

Ealing's historical experiences, alongside its more recent experience during the pandemic, and through local COVID-19 vaccine rollout, hold important lessons for how local actors can work towards building not only greater vaccine equity, but also health equity more broadly in Ealing and NWL. These lessons can be applied to specific interventions such as vaccination campaigns, as well as to routine functioning in and across sectors from health and social care, to economic and political domains. On the whole, they point to more and better quality engagement between stakeholders, both within and between statutory authorities, but especially with local residents and social groups. Below, we list these summary key considerations, drawing on the findings from our review:

- Sustain collaborative and joined up approaches to working. Across the board, local actors stated that increased cross-team collaboration within and between the local authority, NHS and community groups was essential to the success of COVID-19 vaccination, enabling a data-driven and cooperative approach. The bridges built over the last months should be strengthened to support continuing and improved communication, learning, functioning and innovation across sectors in Ealing and NWL. This will support 'whole-systems' understanding of local problems, while collaborative and participatory approaches to priority setting, decision-making and implementation can support success. More can be done to identify community-based leaders, organisations and new initiatives, including smaller and more informal groups/activities that may not be so obvious to authorities, and yet, which may be influential and active in marginalised communities.

- Establish and support mechanisms for more decentralised action. Alongside efforts to bring diverse stakeholders together for collaboration, it is equally important that decentralised activity is supported. As COVID-19 vaccination progressed from a centralised to a more decentralised and agile model adapted for local realities and populations, many more of Ealing's most vulnerable residents were reached. The success of vaccination pop-ups in places frequented by or important to local people for instance, can continue to be deployed to support on-going COVID-19 vaccination, as well as other public health and social priorities. Ealing's undocumented residents in particular, are a key group requiring better support and attention and may be better served by more decentralised, and non-state centric initiatives due to fears of incrimination.

- Emphasise 'going to' communities rather than expecting them to come to authorities. Conventional engagement methods have tended to invite residents to join events like webinars or 
public forums, where information is provided and dialogue facilitated. While important, this often means that only residents who are already engaged, participate. Increase efforts and resources to 'go to' people and community groups, including attending already established platforms and events, and/or setting up in public places and events (e.g. festivals). As vaccination for children commences, showing up in spaces important to families will also be critical. Smaller, less formal groups also require more attention.

- Support community response through facilitation and resources for community organising and participation in local decision-making. Although community groups have played critical roles through their independent organising as well as through partnership with local authorities, their potential is stifled by limited resources and support available to sustain a thriving and resilient civil society. ${ }^{1}$ This is particularly the case for smaller and more informal groups; efforts should thus be made to identify people and organisations perceived to be legitimate figures of authority and to actively engage them in activities from the outset. Additionally, while civil society, community groups and other figures of authority can play an important role in disseminating messages, they should not be treated only as a conduit for top-down messaging, but as active participants in designing campaigns and initiatives when possible, and appropriately compensated for this work.

- Increase attention to vulnerable groups. While impressive efforts were made to ensure important messages about COVID-19 safety measures and vaccination were made and disseminated in a multitude of local languages, this took time. A network of people who can support translation and multi-lingual communication rapidly as well as for routine purposes, supported by resources, can increase the chances for Ealing's diverse cultural/linguistic groups being reached. However, there remain many people who lack access and skills to use digital technology, and much more should be done to engage with them, and tackle the digital divide. Deaf and blind people, and people with other disabilities, also require more tailored communication and opportunities for dialogue.

- Respond to people's multiple needs. Vaccination, or other targeted public health measures, may not be a priority for many in Ealing who struggle with poverty, including in-work poverty, precarious work, and inadequate housing, and other more specific challenges like food security, domestic abuse or lack of opportunities for youth. Aiming to support people more holistically - providing or packaging vaccination services or information alongside other services and vice versa - can also improve their trust in authorities and systems which they may feel have previously failed them.

- Place greater emphasis on qualitative data and resident's lived experience. While quantitative data - especially as disaggregated by area, age, ethnicity and gender - has empowered local authorities and actors to improve vaccine equity, more emphasis on qualitative data is needed. This type of data can contextualise and provide explanation of quantitative data, by illustrating for example, why vaccine uptake is low among specific social groups or areas, thus providing information to adapt response in more context-appropriate ways.

- Encourage and enlist the support of political leadership at the local level. It is critical that residents from across social groups are recognised and supported by political leadership that is demonstrably concerned about their well-being in a holistic sense. Local political actors such as ward councillors can more actively support mobilisation for vaccination and other issues within local areas, and advocate for their constituents of all backgrounds at borough level. Local authorities and NHS structures can also do more politically, including by being actively anti-racist at a local but also national level (e.g. fighting the 'hostile environment').

- Encourage greater engagement of GPs and other local health services. GPs have played critical roles in supporting local COVID-19 response, including vaccination, but have been more active in other boroughs. In Ealing, they may require additional encouragement and support to engage in more joined-up ways of working to support public health and other local priorities. That said, back logs and other pressures they face are immense, and authorities should also be sensitive to this, ensuring that vaccination and other public services are independently catered for. Other health professionals (e.g. dentists, opticians, alternative health providers) could also be engaged to play important roles, including by encouraging their patients to get vaccinated. 


\section{CONTENTS}

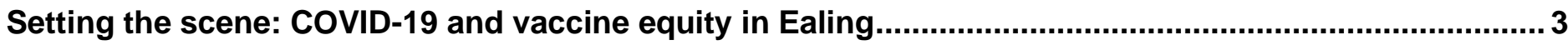

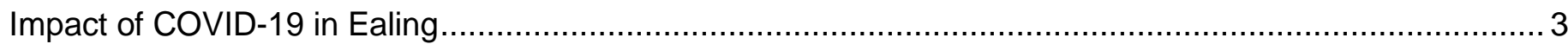

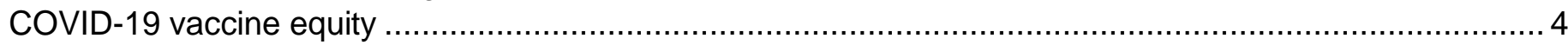

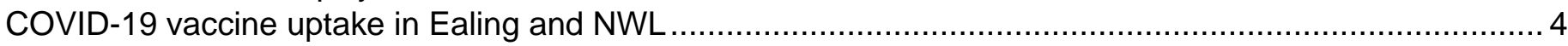

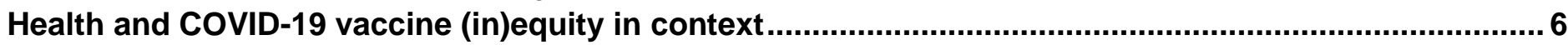

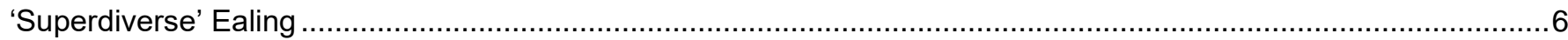

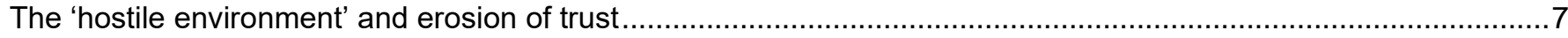

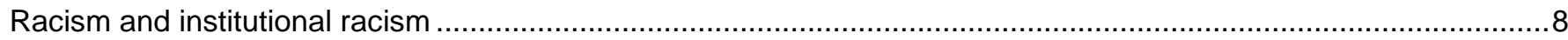

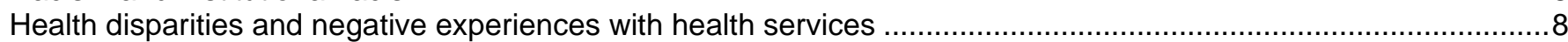

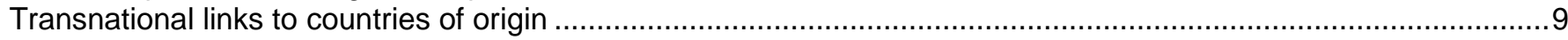

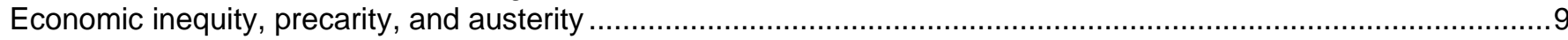

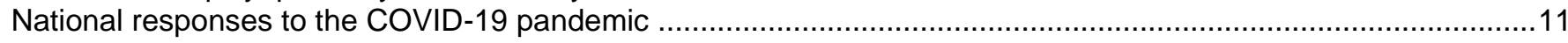

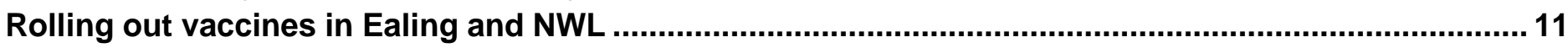

View from the ground: Vaccine (in)equity in Ealing ........................................................................12

Social processes, confidence and trust in vaccines and those producing, promoting and delivering them .. 12

Accessibility, availability and distribution of vaccines and vaccination services...................................... 13

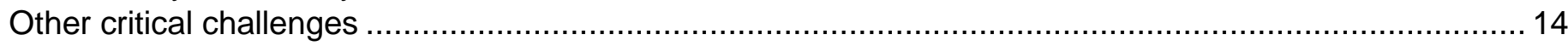

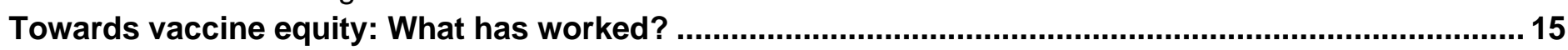

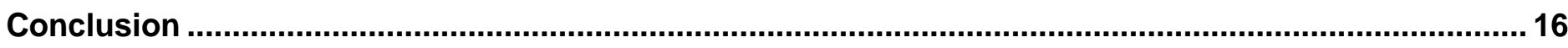

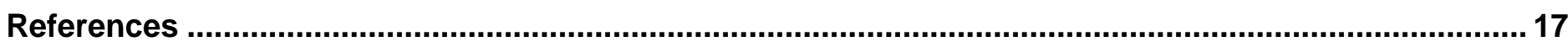

\section{SETTING THE SCENE: COVID-19 AND VACCINE EQUITY IN EALING}

\section{Impact of COVID-19 in Ealing}

The UK's COVID-19 vaccination programme unfolded with pace, and was praised early on. ${ }^{2,3}$ This contrasts to the otherwise tragic outcome of nearly 160,000 UK COVID-19 deaths to date, ${ }^{4}$ attributed by many, including government officials, to national leadership failures. ${ }^{5-10}$ Ealing and NWL were, at times, among the hardest hit localities. To date, Ealing has seen 31,802 cases, with a rate of 14,034.5 per 100,000 people, higher than rates in NWL, London, and England (see Table 1). ${ }^{11}$ There has also been inequality of infection, serious illness and death within Ealing, with the west of the borough being hardest hit.

Table 1. Total number of COVID-19 infections and infection rate per 100k in Ealing, NWL, London and England

\begin{tabular}{|c|c|c|}
\hline Area & $\begin{array}{c}\text { Total number of infections (to 15 } \\
\text { October 2021) }\end{array}$ & Rate per 100,000 people \\
\hline Ealing & 31,802 & $14,034.5$ \\
\hline $\begin{array}{c}\text { North West } \\
\text { London }\end{array}$ & 171,685 & $12,497.9$ \\
\hline London & 728,484 & $12,347.8$ \\
\hline England & $3,917,812$ & 12,364 \\
\hline
\end{tabular}

Table 1 Source: Ealing Covid-19 Dashboard

Across the UK, a disproportionate number of deaths due to COVID-19 have occurred among ethnic minority and deprived people. ii; 12,13 Highly ethnically diverse London boroughs, including Ealing, have 
also had higher than average COVID-19 death rates. ${ }^{14}$ People of black African descent were most impacted in the UK's first wave, with mortality rates 3.7 and 2.6 times greater than those of white British groups (men and women respectively); this reduced to only 1.9 after accounting for several socio-demographic and socio-economic factors. In the second wave, people from Bangladeshi and Pakistani backgrounds faced mortality rates nearly five, and 3.5 times that of white ethnic groups respectively. People from Indian and mixed groups have also had a statistically significant raised risk of death. ${ }^{15}$ Possible explanations for increased impact on Asian relative to black groups include: that black people more frequently work in health and social care where PPE access increased over time, while Asian people more frequently work in other high-exposure but less protected jobs in retail, hospitality and transportation; a higher proportion of multi-generational households among South Asian groups; and the rise of Black Lives Matter which may have contributed to greater mobilisation and solidarity in black communities, while some South Asian groups faced increased stigmatisation related to religious holidays. ${ }^{16}$

Many factors have amplified and interacted to increase COVID-19 risk among these groups, including inequities in health, employment, housing and access to care. ${ }^{16}$ Ethnic minority people are disproportionately employed in high-risk occupations such as cleaning, security, porters, carers, taxi and bus-drivers. ${ }^{17}$ Relative to London and the UK, Ealing in particular has higher proportions of people in higher risk occupation groups, ${ }^{\text {iii; } 18,19}$ with long-term health conditions, ${ }^{20}$ and living in overcrowded households (ranking $8^{\text {th }}$ among London boroughs). ${ }^{21}$ Indeed, nearly half of Ealing's LSOAs (Lower-layer Super Output Areas - small areas of a similar population size) fall within the most deprived deciles for 'barriers to housing and services', while most fall within lower deciles for 'living environment' in the Index of Multiple Deprivation. ${ }^{22}$

\section{COVID-19 vaccine equity}

The concept of 'vaccine equity' refers to fair and just access to vaccines for all people. ${ }^{23}$ In addition to key factors such as the accessibility, availability and distribution of vaccines and vaccination services (along with associated material and human resources), it is also related to other issues with a bearing on vaccine uptake including: : confidence and trust in vaccines and the people and institutions involved in their production, promotion and delivery; and the social processes that influence people's motivation, including information, communication and social norms. ${ }^{24,25}$ Other social and economic inequities, as well as inequities in pandemic response, can shape these dimensions with consequences for vaccine uptake, and thus public health.

While the UK has achieved overall high vaccination uptake, disparities in uptake between social groups have persisted, particularly in relation to ethnicity and deprivation. Nationally, hesitancy has been highest and uptake lowest among people from the most deprived communities and from ethnic minority backgrounds, particularly black groups, followed by South Asian groups. ${ }^{\text {iv; } 26,27}$ Young adults, particularly black young adults, have also been reported more likely to feel hesitant about vaccines. ${ }^{28,29}$ Rather than individual or group failings, this in part reflects historic inequities and ongoing mistrust in and negative experiences with the state and with medical services and health systems, and a failure of public institutions at different levels to adequately engage with and address the concerns and needs of these groups. ${ }^{26,30}$

\section{COVID-19 vaccine uptake in Ealing and NWL}

There are also disparities in COVID-19 vaccine uptake with respect to ethnicity in Ealing and NWL. A study reflecting uptake in NWL up to late February 2020, showed that rates of 'declining' vaccines were highest among black and Black British residents (16.14\%), followed by mixed individuals (10.39\%), 'other ethnic groups' (9.95\%), white groups (4.92\%), and Asian and Asian British groups $(3.21 \%)$. v; 31 The rate of 'declining' vaccines was also over 13 times higher among people living in NWL's most deprived postcodes, versus those in the least deprived, especially elderly black residents. ${ }^{31}$ Figure 1 reflects additional nuance in the uptake and 'decline' percentages among different ethnic groups in NWL up to March 21, 2021 by ethnicity and by deprivation. vi 


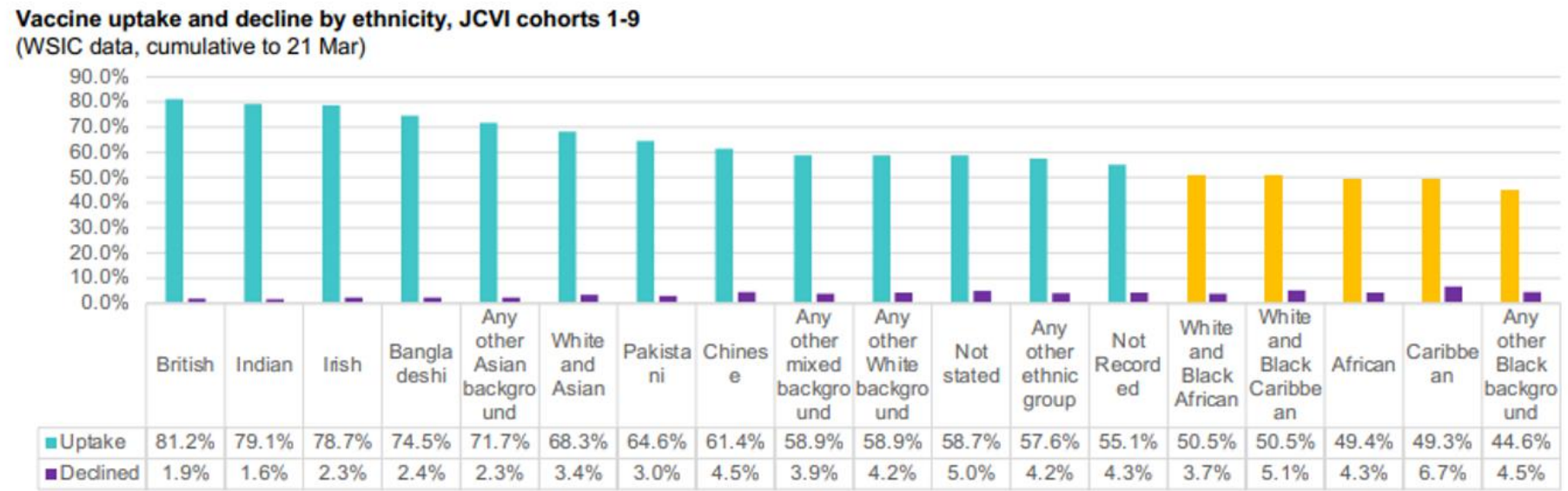

Vaccine uptake and decline by deprivation, JCVI cohorts 1-9

(WSIC data, cumulative to $21 \mathrm{Mar}$ )

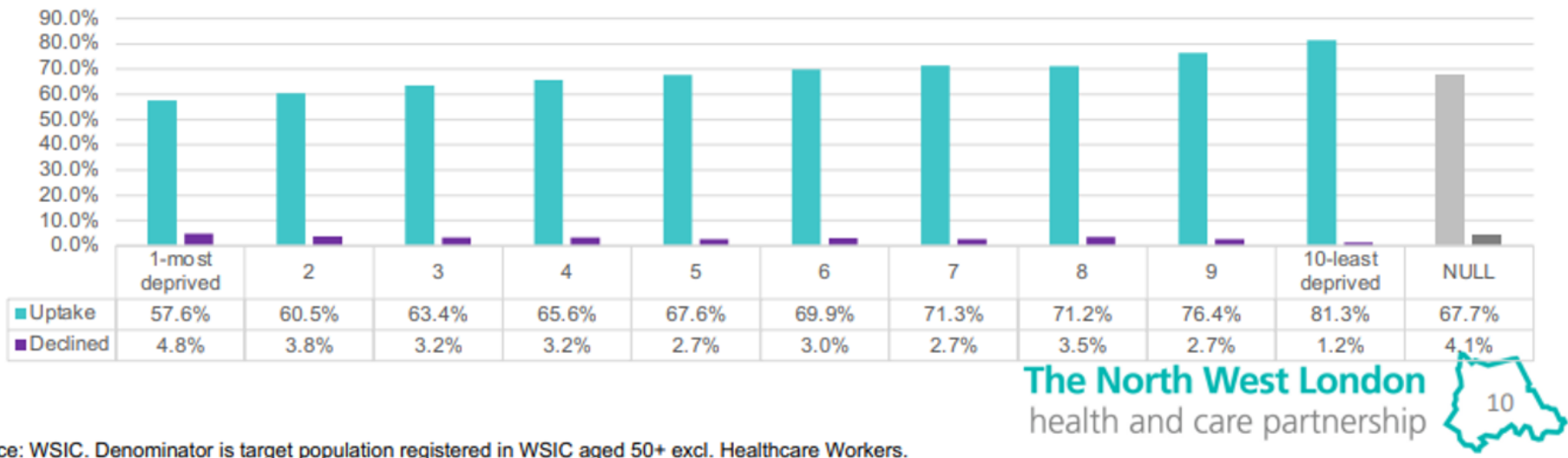

Source: WSIC. Denominator is target population registered in WSIC aged 50+ excl. Healthcare Workers.

Figure 1 tables produced by Imperial College Healthcare Partners using Whole Systems Integrated Care (WISC) data and presented at the NWL Health and Care Partnership's public 'Co-production and Improvement Huddles' for vaccine equity. Publicly available from:

https://www.nwlondonccg.nhs.uk/application/files/5516/1770/2590/NWL_ICS_CoViD_Towards_Vaccine_Equity_Huddles_30.3_synthesis.pdf

As is clear, uptake to that point was lowest among black, or mixed white and black people, and among the most deprived. Fortunately, uptake gaps have narrowed in NWL over time. This is reflected in Figure 2, which shows positive increases in uptake by all ethnic groups over the course of one month (late February to March). vii The largest gains were made among groups which had especially low uptake initially.

Figure 2 Change in vaccine uptake by ethnicity in North West London

Change in vaccine uptake by ethnicity, JCVI cohorts 1-4

(WSIC data $28 \mathrm{Feb}-21 \mathrm{Mar}$ )

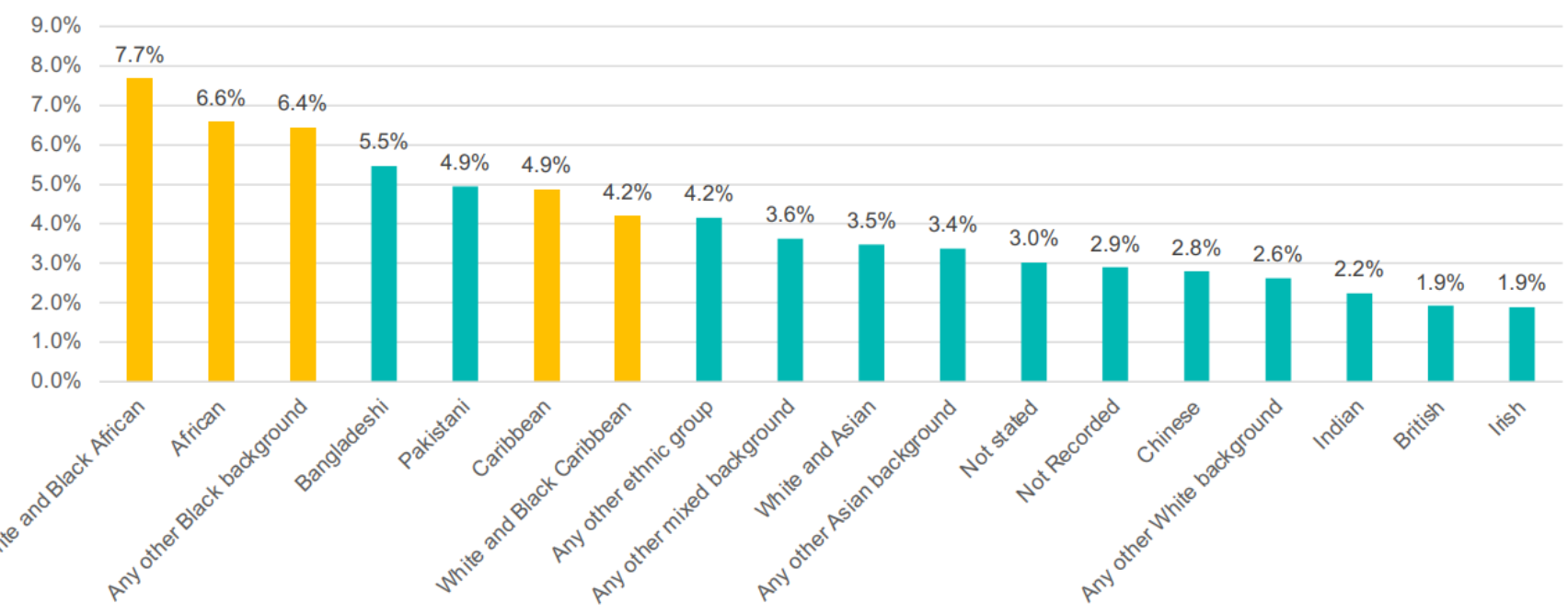

Figure 2 table produced using Whole Systems Integrated Care (WISC) data and presented at the NWL Health and Care Partnership's public 'Coproduction and Improvement Huddles' for vaccine equity

https://www.nwlondonccg.nhs.uk/application/files/5516/1770/2590/NWL_ICS_CoViD_Towards_Vaccine_Equity_Huddles_30.3_synthesis.pdf 
Reasons for this narrowing may include growing confidence in the safety of COVID-19 vaccines over time ${ }^{32}$ and efforts of local responders, health workers and others to better engage with marginalised groups. This is discussed in more detail later.

First, we provide a review of often overlooked contextual factors which may shed light on some of the drivers behind vaccine inequity, as evident in the disparities in uptake.

\section{HEALTH AND COVID-19 VACCINE (IN)EQUITY IN CONTEXT}

Context is critical not just for understanding outcomes such as vaccine inequity, but for shaping solutions. Here we consider aspects of local and national political, social, economic and historical context which influence vaccine equity - and broader health equity - in Ealing and NWL today.

\section{'SUPERDIVERSE’ EALING}

Ealing is a key site of 'superdiversity' - diversity not just of ethnic groups, but within them - of immigration status, labour market experiences, religion, gender, age profiles etc. ${ }^{33}$ Data from the 2011 census showed it was the third most diverse local authority in England and Wales. ${ }^{34}$ It is estimated that $54 \%$ of residents are from ethnic minority (non-white) backgrounds (although $70.9 \%$ of school pupils are), and about $42 \%$ were born abroad, in over 170 countries. ${ }^{35}$ Ealing's migrant groups include longer-established South Asian and Afro-Caribbean residents (arriving in the 1950s and 1960s), and diverse 'new migrants' from Europe, Asia and Africa seeking economic opportunity and asylum (see Table 2 for a population breakdown by ethnicity). The most common non-UK countries of birth in 2011 were India, Poland and Ireland. It is also home to comparably large communities of Afghans and Somalis, relative to elsewhere in the UK. The most common religions are Christian (44\%) Muslim (16\%), Hindu (9\%) and Sikh (8\%). ${ }^{35} 34 \%$ of Ealing residents do not speak English as their first language. ${ }^{36}$

The town of Southall in Ealing's southwest is often called 'Little India' due to its many, longestablished South Asian residents, businesses and cultural institutions. ${ }^{37}$ However, anthropologists have illustrated how diverse groups from AfroCaribbean, Irish, Polish, English and other ethnic and national origins - as well as identity groups coalescing around regional origins, religions, languages, kinship, class and caste - have long occupied the area, thereby calling into question any generalisations about its population. ${ }^{38}$ While Southall has the greatest density of ethnic minority residents, they also make up considerable proportions of the population across Ealing, especially in pockets of Acton, Hanger Hill, Greenford and Northolt (see

\section{Table 2. Overall ethnic group composition in Ealing}

\begin{tabular}{|c|c|c|c|c|c|}
\hline Ethnic Group & Popl & ion & & & \\
\hline White British & $25 \%$ & \multirow{3}{*}{ White } & \multirow{3}{*}{$46 \%$} & \multirow{3}{*}{ White } & \multirow{3}{*}{$46 \%$} \\
\hline White Irish & $3 \%$ & & & & \\
\hline Other White & $18 \%$ & & & & \\
\hline Black African & $5 \%$ & \multirow{5}{*}{ Black } & \multirow{5}{*}{$13 \%$} & \multirow{14}{*}{ BAME } & \multirow{14}{*}{$54 \%$} \\
\hline Black Caribbean & $3 \%$ & & & & \\
\hline Other Black & $2 \%$ & & & & \\
\hline White \& Black African & $1 \%$ & & & & \\
\hline White \& Black Caribbean & $1 \%$ & & & & \\
\hline Indian & $14 \%$ & \multirow{6}{*}{ Asian } & \multirow{6}{*}{$33 \%$} & & \\
\hline Pakistani & $4 \%$ & & & & \\
\hline Bangladeshi & $1 \%$ & & & & \\
\hline Chinese & $1 \%$ & & & & \\
\hline White \& Asian & $1 \%$ & & & & \\
\hline Other Asian & $12 \%$ & & & & \\
\hline Other Mixed & $1 \%$ & Other & $8 \%$ & & \\
\hline Arab & $4 \%$ & & & & \\
\hline Other Ethnic Group & $3 \%$ & & & & \\
\hline Total & $100 \%$ & & & & \\
\hline
\end{tabular}

Table 2 based on GLA 2016-based ethnic group population projections. Adapted from: https://www.ealing.gov.uk/downloads/download/2043/equalities_needs_assessment 


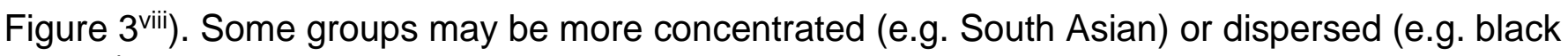
groups) than others.

Figure 3 Percent of population from ethnic minority ('BAME') backgrounds across Ealing, by LSOA (2011 Census data, map provided by Ealing Council)

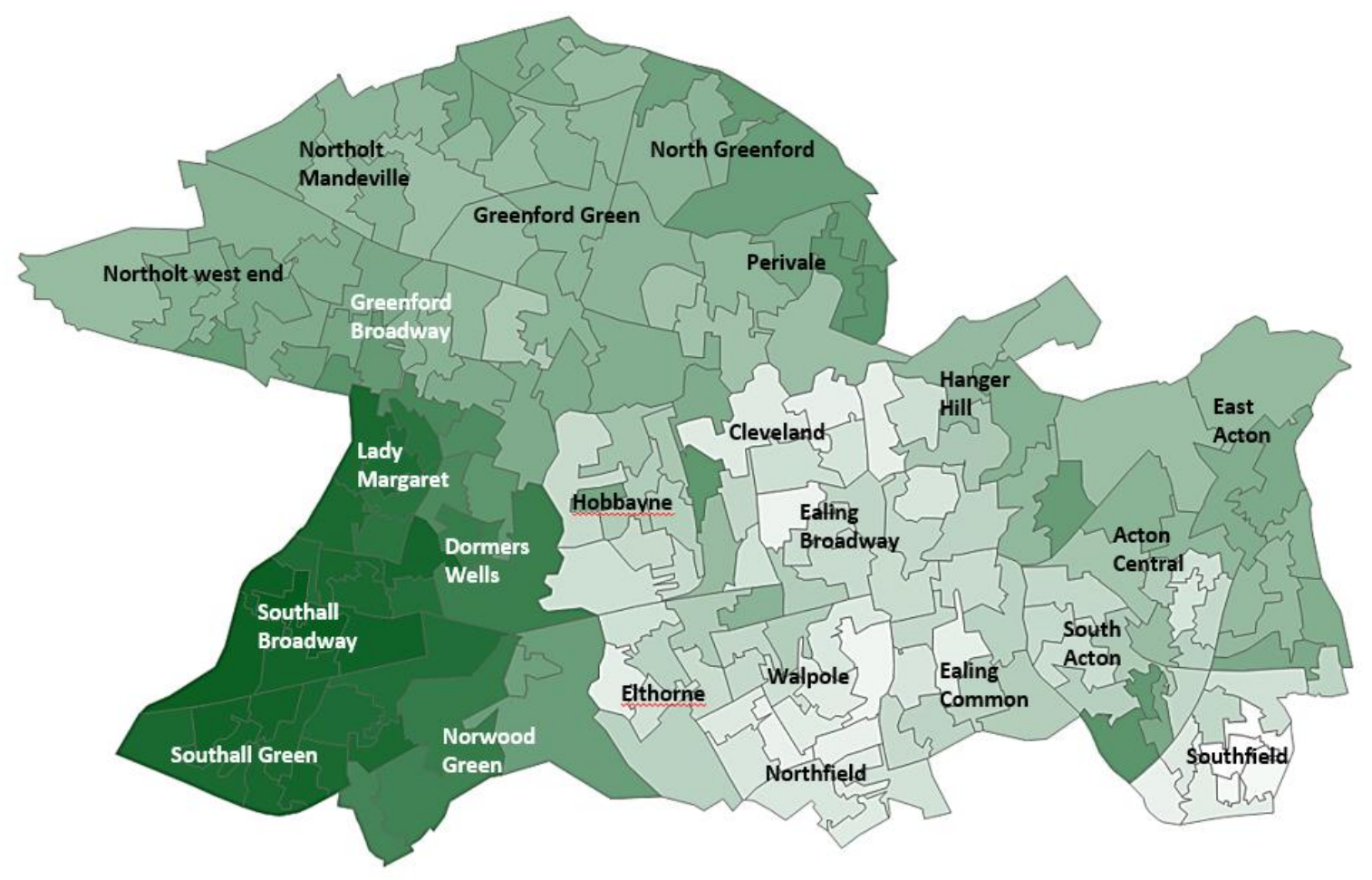

$12.4 \%$
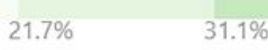

$40.4 \%$

$68.4 \%$

$87.1 \%$

This diversity has had major implications for COVID-19 vaccination in Ealing, as reflected in earlier mentioned lower uptake among ethnic minorities. However, some white groups, such as Polish migrants, numerous in Ealing, may also be more sceptical about COVID-19 vaccines, ${ }^{39}$ or have doubts regarding their eligibility for services or experience language barriers. More limited uptake among ethnic minority groups must be understood in the context of their social and political experiences.

\section{THE 'HOSTILE ENVIRONMENT’ AND EROSION OF TRUST}

These experiences include increasingly hostile restrictions to, and differentiation of, migrant rights and entitlements. ${ }^{40}$ Although beginning with the rollback of post-war open-door policies, especially towards racialised migrants from South Asia and the Caribbean, 'restrictionalism' really gained momentum from the turn of the century. This has included 'no recourse to public funds' for migrants trying to join already settled families, and exclusion of unsuccessful asylum seekers from some secondary healthcare. ${ }^{33}$ The introduction of health service fees for secondary care for migrants without ordinary residence (i.e. indefinite leave to remain), asylum-seekers and refugees, ${ }^{41}$ and datasharing agreements/practices between public services (especially police, but also education and the $\mathrm{NHS}^{42,43}$ ) and the Home Office have significantly impacted migrants' wellbeing with cost, as well as fear of legal consequences (including deportation) delaying/deterring many from seeking needed support. ${ }^{44,45}$ The Ealing-based Southall Black Sisters have reported for instance, that women with insecure migration status avoided seeking healthcare, as well as refuges and other domestic violence protection services in the context of COVID-19.46 Even if entitled to care, many vulnerable migrants are either unaware of what services are available to them, or unable to navigate the increasingly complex system.

Erosion of trust due to negative experiences driven by the broader hostile environment may also impact the extent to which some groups are willing to engage with authorities and public services. The government's poor treatment of the 'Windrush' generation for instance, is likely to have 
particularly marred the trust of the Afro-Caribbean community in the UK. ${ }^{47}$ An example of the impact from NWL comes from anthropological research with unaccompanied Congolese child asylum seekers in Ealing's neighbouring borough of Hillingdon. These vulnerable children experienced their relationship with the local authority responsible for them as 'anything but a close and caring one'. Given minimal resources, and with other priorities, the Hillingdon council could provide only the most basic of housing, minimal subsistence, and impersonal support. ${ }^{48}$ Instead, they learned and gained resilience from each other, through personal relationships with social workers, and in church communities. The lack of care and support from their 'corporate parent' is likely to influence these children's attitudes and trust - and those of others around them - towards public institutions, including government and health system actors.

\section{RACISM AND INSTITUTIONAL RACISM}

Racism, xenophobia and discrimination in broader UK society have also undermined the opportunities and trust of migrants and people from ethnic minority groups. ${ }^{30,49}$ Different groups have been subject to different forms of racism, and to generalise about their experiences can itself further entrench marginalisation. Racism also intersects with gender, class, religion and other aspects of social difference to compound vulnerabilities for many. Institutional racism is evident in the fact that while people from ethnic minority backgrounds make up a substantial proportion of NHS staff, there are few among senior leadership roles. ${ }^{50}$ Their often front-facing roles have put them at higher risk for COVID-19, while research has also suggested they have been less supported and felt more pressured during the pandemic than their white colleagues. ${ }^{51}$

In the context of Ealing, research on migrant and ethnic minorities shows these groups have faced particular challenges and forms of alienation which may shape how they perceive and access formal authorities or public health services, such as vaccination. For instance, research has suggested that some Somali residents have felt particularly under-represented politically, perceiving other minority groups (i.e. Asian) to have greater representation. ${ }^{52}$ That said, Asian groups have also experienced exclusion. An important historical example is that from 1963-1981, Ealing council bussed only South Asian children to schools out their local areas, to 'racially integrate British schools'. However, this was experienced as racist by many local South Asian families. ${ }^{53}$ More recent tensions have revolved around experiences of environmental racism expressed by residents of Southall who have linked cases of breathing problems, chest pain, pneumonia and cancer to pollution in the area. ${ }^{54}$ Issues of racism in housing have also been raised by local organisations led by ethnic minority residents, who have also called out the structural and discriminatory ways in which their organisations - often smaller - are prevented from accessing resources and meaningfully participating in local priority setting and decision-making. ${ }^{55}$

Illustrating that social groups are not homogenous, local women's groups emerged in Ealing to advocate for the rights of migrant and ethnic minority women (particularly South Asian but also AfroCaribbean and women from other minority groups in the area) who have been excluded in critical ways from important gender-based violence services by local authorities, and also within their ethnic communities. ${ }^{56}$

\section{HEALTH DISPARITIES AND NEGATIVE EXPERIENCES WITH HEALTH SERVICES}

Long-standing and in some cases worsening health disparities, such as decreasing life expectancy among the poorest, have been linked to austerity, and resulting deterioration of social and economic conditions in housing, education, employment and child poverty. ${ }^{57}$ Health disparities are also racialised. ${ }^{58}$ Diabetes for instance, is much higher among South Asian and black groups than white groups, ${ }^{59}$ while maternal mortality is nearly five times as high among black women than white women in the UK. ${ }^{60}$ Rather than being genetic, these health disparities are bio-social in nature and emerge through intermediate inequities linked to socio-economic deprivation - diet, stress, working and living environments, access to information, education, social capital, air pollution, and so on.

That said, while socio-economic deprivation and its many consequences contribute to racial health disparities in major ways, some discrepancies persist even when these variables are controlled for, clearly highlighting the role of racism. ${ }^{58,61}$ 
Social science research has also demonstrated that migrants and people from ethnic minority groups may struggle to access health services or have negative experiences of them. For instance, UK research with 'new migrants' revealed problems understanding how to register or get an appointment with a GP, how the NHS is organised, and what services are available or free to them.

Communication challenges including linguistic and inter-cultural misunderstandings (and unreliable interpretation services), have also been documented to lead to inappropriate treatment or patients feeling misunderstood and dismissed. ${ }^{33}$ Non-migrants may also feel dismissed and devalued by doctors perceived as uncaring and overloaded, and may withdraw entirely, sometimes to seek private alternatives if affordable. ${ }^{62}$

Research on eye health seeking practices among Southall's Indian immigrant population revealed frustrations with long waits, linguistic challenges, GPs not explaining things or not following up with promised referrals, and patients' records being lost by local hospitals. ${ }^{63}$

Trust is an important theme in social science research on health seeking. When people do not trust their physicians, they may be more likely to turn to the internet, ${ }^{64}$ and thus potentially be more exposed to misinformation. People may also turn to a range of trusted family, friends, and others in their community in addition to physicians, with these encounters also influencing their health decisions. ${ }^{65}$ This underscores the importance of engaging with communities around important public health issues like COVID-19 vaccination, even when people do engage with GPs.

\section{TRANSNATIONAL LINKS TO COUNTRIES OF ORIGIN}

Given the diversity of ethnic and migrant populations in Ealing, the histories, cultures, networks and institutions of residents' countries of origin, to which many may remain closely linked, may also influence their orientation to COVID-19 vaccination and other health services in the UK. Research has documented migrants viewing media programmes or seeking doctors from their home countries, or returning there for care. ${ }^{33,66}$ The ways in which other countries deliver health services - including COVID-19 vaccinations - may differ from UK's approach, causing confusion and scepticism.

Historical experiences of poorly run vaccination or medical trials/campaigns in other countries can have lasting consequences for people's trust in vaccines, health workers, authorities and international actors involved in, or perceived to be involved in the vaccination campaigns. ${ }^{67}$ Broader political histories, such as experiences of war, national disintegration, or corruption of authorities may also result in people having limited trust in public and private actors, in whatever country they are in. In Poland, nearly half the population expressed COVID-19 vaccine hesitancy in December 2020. This has been linked to Poland's turbulent political history, having been under 'malevolent foreign domination' for much of the last 250 years. ${ }^{39}$ Polish and other Eastern European communities in the UK also tend to have lower routine vaccination rates which may be linked not only to linguistic barriers and information challenges, but to differences between Polish and UK vaccination services and procedures. ${ }^{68}$

\section{ECONOMIC INEQUITY, PRECARITY, AND AUSTERITY}

Another important driver of disparities in vaccine uptake is a lack of economic opportunities for many, and increases in precarious work across the UK. ${ }^{69}$ This leads to economic insecurity which impedes people's ability to meet their basic needs. Economic inequality also has independent negative social impacts including decreased trust in public institutions and within communities. ${ }^{70}$ Already vulnerable groups such as women, young people, migrants and ethnic minorities are disproportionately affected by economic precarity in the UK. For instance, 1 in 8 black people were in insecure employment in 2016 (UK average, 1 in 17). ${ }^{71}$ The pandemic exacerbated economic conditions for many. Young people, likelier to work in sectors impacted by pandemic control measures and less able to work from home, have lost more jobs. ${ }^{72}$ In January 2021, 20\% of Ealing's residents (33,300 workers) were on furlough - the second highest of all London boroughs, and the highest in West London. ${ }^{73}$ Economic hardship may be a more pressing issue for people than vaccination, or other public or individual health concerns. Failure to provide adequate economic support can further damage people's trust in public institutions and services.

Pandemic impacts also come after years of austerity - funding rollbacks and increasing restrictions to national and local spending on key services in unemployment, housing, health and social care, elder pension support, asylum services and more. ${ }^{74}$ London boroughs may have experienced a $63 \%$ reduction in real terms to their core funding from government in the last decade. ${ }^{75}$ Vulnerable groups such as unemployed people, disabled people, those with long-term health conditions, asylum 
seekers, children, and women and families experiencing domestic abuse have been among the most impacted. ${ }^{76-79}$ Chipping away at social safety nets and services for vulnerable people is likely to impact their trust in public institutions, and may reasonably lead them to question seemingly sudden interest in their wellbeing when trying to persuade them to engage in health interventions, such as COVID-19 vaccination.

Economic history of Ealing. Ealing was incorporated into a sprawling London in the $19^{\text {th }}$ century. Initially a market garden for the metropolis and then an affluent suburb, it eventually became popular for businesses, particularly in food manufacturing, health and logistics. ${ }^{80} 8.9 \%$ of Ealing's jobs remain in manufacturing, compared to $2.3 \%$ of London's overall. ${ }^{81}$ The Park Royal industrial estate (the largest in London and shared by Brent and Ealing) hosts around 2,000 mostly small and medium companies employing over 30,000 people. ${ }^{82}$ Many serve Heathrow Airport, and have been severely impacted during the pandemic. ${ }^{22}$ Mirroring the borough's diversity, $40 \%$ of Park Royal businesses are owned by ethnic minority people. ${ }^{80}$ While $69.3 \%$ of those employed in manufacturing occupy managerial, professional and technical roles (London average, 63.1\%), lower paid jobs in machine operation and other 'elementary occupations' iii amount to $13.7 \%$ (London average, 9.8\%). ${ }^{81}$

Poverty, unemployment and deprivation in Ealing. Ealing is ranked as the $87^{\text {th }}$ most deprived English local authority (out of a total of 326 local authorities) in the 2015 IMD. The most deprived areas fall within the towns of Northolt, Southall, and Acton. Norwood Green is the most deprived ward in terms of overall IMD score, followed by Northolt West End, Southall Broadway, and Southall Green. ${ }^{83}$ Poverty rates in the borough after housing costs are $40 \%$; pay inequality (80:20 ratio of earnings) is 2.67 while income inequality is equal to London. ${ }^{84}$

From January to December $2020,6.3 \%$ of the economically active population of Ealing were unemployed, compared to $5.9 \%$ in London, and $4.6 \%$ across Britain. Men are more likely to be formally employed ( $84.8 \%$ of economically active) than women (66.1\% of economically active). ${ }^{81}$ Being ineligible to work, asylum-seekers, of which there were 202 receiving Section 95 support in Ealing in 2017, are at risk of destitution until their claim is resolved ${ }^{85}$ Employment rates also differ by ethnicity. In 2019, while Ealing's overall employment rate was $74.3 \%, 79.2 \%$ of white residents were employed, compared to $66.8 \%$ of those from ethnic minority backgrounds. More specifically, $72.7 \%$ of Indians, $56.2 \%$ of black and black British, and just $46 \%$ of Pakistanis and Bangladeshis were in employment. ${ }^{86}$ Ealing had more people on Universal Credit - 10.3\% of all inhabitants in April 2021 than London overall (8.3\%). ${ }^{81}$ Long-term unemployment is a standing issue in Ealing, with nearly three quarters of job seekers claimants in March 2020 having been unemployed for over two years a proportion much higher than other West London boroughs, London and the UK by large margins. ${ }^{22}$ Pandemic lockdowns meant many people could not access unemployment centres in person for support with employment and Universal Credit. This was particularly difficult as access to digital technology and digital literacy is low for some populations in Ealing.

Precarity and in-work poverty. While $71.1 \%$ of people in employment in Ealing are employed fulltime, part-time employment is more frequent $(28.9 \%$ of employed) than London overall $(25.9 \%)$. The 'gig economy' has also taken root. Ealing itself experienced the greatest rise in self-employment in

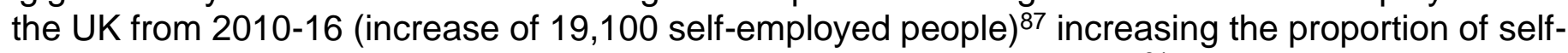
employment from $10.5 \%$ in December 2005, to $14 \%$ in December $2020 .{ }^{81}$ Self-employment tends to be concentrated in manufacturing, construction and transport, sectors vulnerable to the economic impacts of the pandemic. The proportion of people on zero-hour contracts in London has also grown from $0.4 \%$ of employed people in 2010 , to $3.2 \%$ in $2020 .{ }^{88}$ In Ealing's social care sector, $49 \%$ of workers are on zero-hour contracts (compared to $42 \%$ in London, and $25 \%$ in England). 89

Access to the government furlough scheme has been particularly challenging for people in precarious work or living situations as they may not have documentation for past earnings (e.g. for selfemployment) or current needs (rent paid in cash). As furlough was left at the discretion of employers and not a right, many workers were left with a sense of uncertainty and powerlessness. ${ }^{90}$ Precarity and low wages also mean that being in work does not necessarily deliver freedom from poverty. In $2018,30.2 \%$ of Ealing's workforce (31,000 people) were in in-work poverty, compared to London's $20.4 \%$. Additionally, like London, Ealing's population is younger on average than the UK overall; young people are more likely to be in low-paid and insecure work, and thus at greater risk of being 
unable to meet their basic needs. ${ }^{91}$ Other vulnerable populations like undocumented migrants are also more likely to have precarious and informal contract arrangements,. ${ }^{92}$ Those in such precarious low paid jobs or family businesses may be less able to self-isolate or find time to seek vaccination within working hours.

Overall, economic life in Ealing, especially issues of long-term unemployment, inadequate housing (in terms of both supply and conditions), rising rates of self-employment, zero-hours contracts and projected declines in manufacturing, means many residents face precarious circumstances. The medium- and long-term economic fallout of the pandemic will likely exacerbate this for many. Difficult economic experiences in the past, and continued lack of adequate support and limited opportunities accentuate insecurity and are likely to further damage people's trust in the public institutions that have, or which they may perceive to have, failed them.

\section{NATIONAL RESPONSES TO THE COVID-19 PANDEMIC}

Finally, vaccine inequity, particularly the dimension relating to people's confidence in COVID-19 vaccines, cannot be considered outside the context of the national government's handling of the response. Although the UK's vaccination programme was among the first to make significant headway, the substantial loss of life and the government's early downplaying of the severity of the crisis and decisions to delay key public health interventions damaged its own credibility in the eyes of many citizens. This included confusing messaging, ${ }^{93}$ and stigmatising narratives, in which minoritised ethnic communities were blamed for causing or spreading COVID-19.94 There was a lack of transparency in decision-making, delays to important action (economic support for people losing work and self-isolating, school meal support), failed testing and contact tracing efforts, and corruption. ${ }^{5}$

Furthermore, as it became clear the virus was disproportionately impacting people from ethnic minority groups, the government's failure to recognise racism and institutional racism as drivers of these disparities may have further damaged the trust of these groups in particular, in the national government. ${ }^{95}$ Additionally, the government's promise not to carry out status checks on undocumented migrants to encourage them to get vaccinated, may have done little to sway them. Organisations working with this population contend they have had little reason to trust the state on this, ${ }^{96}$ and evidence collected by the Joint Council for the Welfare of Immigrants showed that $43 \%$ of surveyed migrants reported being scared to access healthcare if they got sick during the pandemic, especially those from Africa and the Caribbean (60\%), and from Asia (56\%). This included $30 \%$ of those with visas and entitled to care. ${ }^{97}$

\section{ROLLING OUT VACCINES IN EALING AND NWL}

Ealing's COVID-19 vaccination rollout began with two central sites selected by the NWL Clinical Commissioning Group (CCG) (which is ultimately responsible for COVID-19 vaccination campaigns in the region): the town hall in New Broadway, and the Dominion Centre, an arts and community centre in Southall. The selection of a site in Southall was considered important due to recognition that the area suffered disproportionately from COVID-19 infection, illness and death, and its large ethnic minority population whom decision makers wanted to ensure had access to vaccines. Several GPs across the borough's eight Primary Care Networks (PCNs) worked together to conduct vaccination within the hubs at Ealing Town Hall and Dominion Centre until May, when they stopped these services due to the need to focus on routine health services and business as usual work. As the campaign has progressed, spurred on by national targets set by NHS England, it has shifted towards a more decentralised model of delivery, combining core provision in vaccination centres, community pharmacies and pop-up sites in various locations across the community. During the time of writing, the areas of Acton, Northolt and Greenford were specifically targeted for these kinds of initiatives due to lower rates of take-up in comparison with the rest of the borough, including Southall.

While the NWL CCG is ultimately responsible for COVID-19 vaccination campaigns in the NWL region, Ealing Council and other key partners also collaborated and played critical roles in supporting the logistics, communication and engagement efforts of the campaign. A Vaccination Working Group including members of the council's Public Health, Communications, Community Engagement and 
other teams and departments, meets regularly to discuss progress and challenges, and to plan actions and make key decisions in line with the guidance of the CCG. Efforts to communicate and engage with various community organisations, social groups and areas through door-to-door leafletting, handing out testing kits, radio call-in shows and hosting and supporting webinars have been made. Local organisations, such as Ealing Healthwatch have also supported campaigns, and translated materials into various languages to reach different linguistic populations. Engagement efforts have also been supported by a range of community-based groups, including $\mathrm{EACH}$, and the council's Kick-Start apprentices who have engaged in conversations with local people to understand their attitudes to vaccinations, and to take suggestions to improve access and engagement.

\section{VIEW FROM THE GROUND: VACCINE (IN)EQUITY IN EALING}

At the time of writing, $64.5 \%$ of Ealing's population (aged 12+) had been vaccinated with one dose, and $57.4 \%$ with two doses. ${ }^{\text {ix; }} 98$ Despite a substantial number of people without even one dose (including $16 \%$ of over $18 \mathrm{~s}$ ), people we spoke to suggested that many fewer people have been coming forward, and that it has become difficult to know where these missing individuals are, and how best to reach them.

\section{Social processes, confidence and trust in vaccines and those producing, promoting and delivering them}

Limited data. While some understanding of why many Ealing residents have still not received or taken up COVID-19 vaccines has emerged through community engagement activities, more systematic understanding has been limited. In contrast with readily available quantitative data illustrating how many vaccines have been administered or 'declined' when offered, such qualitative insight has filtered through to decision makers in a more ad hoc manner, and often through informal channels. This was noted by several people we spoke with, several of whom did not feel comfortable commenting on the reasons behind local people's vaccine hesitancy for this reason - and thus highlighting the need for more localised, systematic research in this area.

That said, through their various engagements with local leaders and organisations, and listening on the ground, those involved in the rollout that we spoke to did report several interrelated confidence/trust related factors, which they perceived to be behind vaccine hesitancy in Ealing:

Fears over vaccine safety. Local actors mentioned hearing of fear of needles and vaccine sideeffects. They also encountered people who believed negative health outcomes or deaths they had witnessed or heard about had resulted from COVID-19 vaccines. Some heard from people that they would rather wait for herd immunity than risk vaccination, while others preferred to avoid specific vaccines. Fear linked to mistrust. Some of this fear was based in mistrust in the intentions of pharmaceutical firms, the medical profession or other official public authorities. From black community members in particular, people we consulted heard about tragic and unethical past events, such as medical experimentation on black U.S. Americans, and ill-fated pharmaceutical trials (Pfizer trials $\left.{ }^{x}\right)$. A comment made by Matt Hancock that black people should receive vaccines first, exacerbated these worries among a local Afro-Caribbean group in Northolt.

Mistrust due to exclusion and abandonment. This mistrust is distinguished from that linked to fear of vaccines or suspicion of authorities' intentions. It is rather a reactive form of non-compliance, due to having felt disregarded/dismissed. One individual we spoke to, who has long worked with local youth, noted austerity-linked impacts including defunding of youth programmes and centres, limited opportunities, and the exclusion of youth concerns and experiences throughout the pandemic as reasons for eroded trust among youth. The question of 'Why now?' was also evoked in regional meetings of various authorities, NHS and community members in relation to migrant and ethnic minority communities in NWL. Having been directly and indirectly excluded from key services, support and opportunities, there is suspicion about what may seem like the sudden interest of authorities in the wellbeing of marginalised groups. 
Fear of incrimination or deportation. This was a strong theme expressed by people we consulted, illustrated by the recognition of a large 'unregistered' population who began attending the later deployed vaccination pop-up and walk-in sites. At these events, people could receive vaccines without giving personal information, such as their name or address. This revealed to local authorities the scale of the undocumented population, and their concerns about being identified as such, and potentially incriminated or deported.

Local actors also mentioned other factors which they felt may have shaped local people's confidence in vaccines and authorities:

Hesitancy or delays in sharing key information. Due to worries of creating panic, or that people may misinterpret or fail to understand important caveats to some information and data, some we spoke to suggested there has been a tendency to hesitate or delay releasing key information (and withholding some altogether), such as the presence/spread of the Delta variant within Ealing. Perceived delays may have the effect of making it seem as if authorities are intentionally hiding information, and may mean that people look to other sources for information.

Assumptions about trusted actors. At the regional level, concerns were expressed about whether people in communities actually trusted the 'leaders' or 'community champions' with which authorities engaged to spread messages about vaccination and other pandemic control measures. Although it did not actually come to fruition due to the intervention of community engagement leads, a specific example of how such an assumption might have negatively impacted local trust occurred during Ramadan. The British Islamic Medical Association, a national body, suggested Muslims could carry out an alternative to Taraaweeh prayers at a mosque, by following them on television or online at home. Council teams prepared to disseminate and promote these alternatives on the assumption that local Muslim groups would trust this institution. In reality, many Muslims do not trust this national body as they are often seen as too willing to compromise the faith in order to fulfil the needs of the government.

Diasporic links. As earlier mentioned, diasporic links among migrant and ethnic minority groups with networks or media from their home countries has also shaped people's feelings about vaccination. For instance, one Somali group in Ealing insisted on the endorsement of a specific Islamic scholar from Somalia. At the NWL level, GPs reported patients hesitating due to inconsistencies between information and strategies in the UK, and those in their home countries (e.g. with respect to the delivery of the Astra Zeneca COVID-19 vaccine).

\section{Accessibility, availability and distribution of vaccines and vaccination services}

Most of the individuals we consulted emphasised that people's confidence in vaccines and their willingness to take them has increased over time, and indeed, this is borne out by the data. However, another key issue influencing vaccination take-up in Ealing - like other health services more broadly - is how accessible they are for people who live and work in diverse, and often challenging circumstances. Some challenges to this aspect of equity as suggested by those we spoke with in Ealing are detailed below.

Primary Care Networks (PCN) engagement. At the outset of the vaccination programme, several GPs across the borough's PCNs worked to provide COVID-19 vaccination, ensuring there were more options for people than just two mass sites. Provision by GPs may also increase confidence; one UK poll suggested people may be more receptive to COVID-19 vaccination if encouraged by their GP. ${ }^{100}$ People we spoke with also mentioned being surprised to learn how many people did not travel far from work or home, and that getting to mass vaccination sites would thus likely pose challenges for them. However, the PCNs had to limit their involvement to prioritise the many other health services they provide. While it is certainly critical to ensure continued provision of other key services, the loss of community-embedded COVID-19 vaccination services left a gap in provision which responders struggled to fill. Healthwatch confirmed that lack of transportation to mass sites was a barrier to access for many in the UK. ${ }^{101}$ People we spoke to confirmed this was also an issue in Ealing. Additionally, other nearby areas such as Hounslow, have had a number of highly engaged activist GPs who have mobilised and supported a range of vaccination activities and initiatives, whereas 
similar actors have not emerged in Ealing. Those we consulted lamented this, and the limited scope for more joined-up ways of working with PCNs and GP surgeries who are, under the current model, relatively autonomous and independently choose what services to provide. Engagement is based on good-faith and must be balanced with the economic and workload demands on GP surgeries.

Uneven coverage across the borough. Initial concern to ensure vaccination in Southall due to its many undocumented/unregistered as well ethnic minority residents was warranted and critical.

However, some people we consulted felt this concentration on Southall meant that other vulnerable areas of Ealing like Acton, Greenford and Northolt have been relatively underserved. These areas are also home to many people from ethnic minority, migrant and deprived backgrounds, and data suggests uptake in these areas, particularly Acton which has higher concentrations of black residents, has remained lower than average. ${ }^{102}$ Individuals we consulted described these areas, and the challenges faced by people who live in them, as more 'hidden' than those in Southall, which as an area has had many active community groups, and a relatively strong political voice over the years. Some have also pointed to potentially greater acceptance of biomedical interventions among South Asian groups (more concentrated in Southall) in the main, perhaps partly related to the high proportion of people from South Asian backgrounds in medical professions. Fewer suitable sites for vaccination, particularly in Acton, also presented logistical barriers to serving these areas. In addition to the geographical distance of vaccination sites, the time-frames during which vaccination has been available (usually normal working hours and sometimes into early evening) has not necessarily suited the realities of many people who may struggle, for instance, to take time away from work, or who have caring responsibilities. The lack of appropriate and affordable transport links to vaccination centres has been another important factor.

Chasing targets and political approval. Some we spoke to also talked about the ways in which numerical targets (e.g. the number of people within Ealing who should be vaccinated by a specific date) have spurred action, while also having perverse effects. This includes orientating responders towards large scale and highly standardised models of delivery, rather than providing space to take a more equitable approach which involves focusing on and addressing the needs of vulnerable groups including ethnic minority, migrant and unregistered groups. Similarly, external political pressure to achieve targets, and to be seen to be performing well, has reinforced a one-size-fits-all approach.

Recognition is not action. One person we spoke to lamented that while there has over time been increasing recognition of the critical challenges around vaccine equity and what could be done, this has not been met with adequate action. For this person, 'hard to reach groups' only remain hard to reach because they continue to be excluded from standardised models of engagement.

\section{Other critical challenges}

Other logistical, resource and institutional challenges can impact vaccine equity.

Staff overwork and burnout. Although steadfastly committed, NHS professionals leading the COVID-19 vaccination rollout - on top of their normal and other pandemic related responsibilities have been severely overworked and under-resourced, leading to risk of burnout. Loss of capacity and motivation to respond could result in lesser attention to the specific needs and concerns of vulnerable groups for which standard channels are inappropriate.

Limited support and communication from the national level. Throughout the pandemic, shifts in strategy from the national level have occurred suddenly and without the consultation of, or specific communication with, regional and local teams. Responders we spoke to reported learning of changes - for which they were responsible to implement - as national officials announced them publicly (e.g. that under-40s should be offered a vaccine other than Astra Zeneca). This sent them scrambling to put in place changes within hours, increasing stress, and potentially reducing chances for success.

Logistical challenges. Issues related to vaccine supply and transportation, including anticipating how much would be needed at a pop-up clinic, has been challenging. At times, many more people than expected have showed up to pop-up sites, and have had to be turned away (although staff have made efforts to set them up with appointments elsewhere). Other examples have included not having 
appropriate vaccines for under-40s, or indeed, having alternative options for people who may be uncomfortable with a specific vaccine.

\section{TOWARDS VACCINE EQUITY: WHAT HAS WORKED?}

While there have been considerable challenges, as mentioned, the vaccine rollout has also been quite successful across the UK and in Ealing. However, as the Delta variant, and looser public health measures (including the return of many face-to-face activities) continue to drive up cases across the country at the time of writing, it is urgent that vaccination efforts continue, stepping up efforts to reach those as yet unvaccinated, those who require second doses, and increasingly, those who require boosters. Below are some of the strategies and techniques felt to have been successful by local actors, particularly with regard to reaching vulnerable groups and improving vaccine equity.

From centralised to decentralised models of delivery. As already mentioned, vaccine delivery in Ealing has shifted from two mass sites at the outset (and some surgery-based delivery), to a more flexible and agile model with pop-ups and walk-in clinics (including a vaccine bus which also plays a visible promotional role) in locations across the borough. These have included places of worship, schools, pharmacies and even supermarket parking lots. Initial resistance to a more decentralised model because of worries about inefficiency (fewer vaccinations for the resources required), was overcome when an initial trial of a pop-up site in Southall saw the attendance of over a thousand people, many of whom were unregistered. While not all pop-ups have had quite as many attendees, one individual told us that a lesson learned over time has been the recognition that 'you need to spend $80 \%$ of your resources to reach $20 \%$ of the population'. Many people reached through these channels have been those that would have been much less likely to have been vaccinated in a timely way, through normal routes.

\section{Communicating that registration/identification is not necessary. Substantial numbers of} unregistered people in the borough, especially undocumented migrants, but also including rough sleepers and people who simply do not want to be registered with the NHS for whatever reason, have come forward for vaccination after being reassured they would not need to present identification. Concerns about the way in which some groups (e.g. Polish) may attribute different meanings to terms such as 'walk-in' or 'no registration' have emerged from community engagement efforts, and discussion about how to handle this is underway.

Active listening to people on the ground was repeatedly mentioned by responders we spoke to as an important, if mainly ad hoc activity (apart from in the case of a few people directly involved in community engagement who did this consistently). This occurred through webinars hosted publicly or for/with specific groups, or visiting vaccination sites and talking to and listening to people. This provided responders with a sense of what the concerns of local people were regarding not only COVID-19 vaccination, but also other priorities and challenges they faced. For instance, it became clear that transportation to vaccination sites was a challenge for many in the community; in light of this, responders were able to mobilise local transportation resources to support those in need. At the same time, others noted that some in migrant and minority groups have at times felt as if they were constantly being consulted, and frustrated that this did not appear to lead to change.

Community engagement. Although dedicated community engagement teams are small and have few resources, engagement with local community leaders, especially faith leaders, was seen to be a highly valuable activity that supported the dissemination of critical information through local networks, while also feeding information about community concerns to responders. The limitations of engagement with community leaders, in that this did not necessarily guarantee that all, and especially more vulnerable residents, were reached, was complemented with a range of open public forums (e.g. webinars) hosted both by local authorities and community organisations, as well as various engagements with smaller, specific groups. The latter included a meeting with a local Somali group about COVID-19 vaccination. Authorities initially hesitated to meet with them, due to the small numbers of attendees. This group also requested the presence of a Somali Islamic scholar. Although a challenge to arrange, the group came away feeling much more confident in the vaccines (having been initially very hesitant), and thus illustrating the principle that resource-intensive engagement is 
often necessary if responders are serious about vaccine equity, and reaching smaller vulnerable groups within a broader 'superdiverse' community. That said, individuals we spoke to, particularly those in community organisations, stressed the importance of going to community groups rather than expecting them to come to the council which can result in only the 'usual suspects' being present. Additionally, experience with Community Champions models in the context of COVID-19 illustrates the need to get beyond assumptions about who is locally trusted and influential as this may not necessarily be those in more traditional community leadership roles. ${ }^{103}$ Work is required work to identify less obvious yet influential community actors which might include shopkeepers, hairdressers, sports coaches or others.

Collaborative, flexible and joined-up approaches to working. Responders we spoke to described the more regular engagement between different teams within the council, as well as between the council and the CCG throughout the pandemic as having been extremely helpful in managing the crisis. Although it could be challenging, and power relations still shaped whose voices and knowledge were more or less valued in these interactions within and between both institutions, the overall sense was that opportunities to communicate and share more regularly led to improved relations, appreciation for the work done by different teams, and higher quality response. Cross-region engagement, such as the NWL Co-production and Improve Huddles for Vaccine Equity, also provided opportunities to learn from strategies taken in other areas, such as pop-up sites, vaccination bus, supporting rough sleepers, and to link in with initiatives elsewhere (e.g. webinars hosted by groups in other boroughs like Hounslow).

\section{Supporting/working with community groups. Formal responders also described actively} supporting or working with community groups to deliver services in the community. They were described as more agile and responsive, and as very keen to get involved throughout the pandemic to respond to the multiple needs of local people, such as access to food. Although centred in North Kensington, one initiative dubbed Community Immunity entailed partnerships between local NHS actors, and trusted community organisations such as the Al-Manaar Muslim Cultural Heritage Centre which played a critical role in the wake of the Grenfell disaster, and Nishkan SWAT which works with homeless people. Webinars, pop-up vaccination clinics (including in the Al-Manaar mosque), a 'vaxi taxi', a phone line to help people book appointments, and initiatives to provide vaccination as well as more holistic support to rough sleepers have been some of their activities. While community organisations (including smaller and informal ones) can play important mobilising roles, they must be properly resourced, and compensated for their time. Smaller, and more informal organisations may struggle to gain access to resources, despite playing key roles in their communities. ${ }^{55}$

Taking a data driven approach. Local responders have drawn on a wealth of data, especially on COVID-19 transmission and vaccination uptake among different groups and in different areas of Ealing, to shape their activities. Indeed, lower uptake in areas such as Acton are what have oriented more recent efforts towards these areas. As quantitative data comes in from Public Health England, among other sources (such as local watchdog Ealing Healthwatch), it is analysed, presented and discussed among multi-sectoral teams within the local authority on a daily, or several-times-a-week basis. Responders we spoke to described this as invaluable, and stated it has increased the profile of data management teams, and the importance of following an evidence-based approach. More emphasis on qualitative data which contextualises and explains quantitative data however, is needed.

\section{CONCLUSION}

This review has aimed to contextualise COVID-19 vaccination in Ealing - and in particular, the disparities in uptake between different social groups - to reveal lessons for local actors aiming to achieve greater vaccine equity locally. By appreciating Ealing's social, economic and political past and present, and recognising the challenges and successes of the COVID-19 vaccination rollout to date, a number of key considerations emerge. Broadly, these include a need to integrate sensitivity to the distinct needs and concerns of Ealing's diverse social groups; to sustain collaborative working across teams, organisations and sectors; and to build trust with and meaningfully engage citizens especially the most vulnerable groups. These key considerations are further detailed at the beginning 


\section{ENDNOTES}

' Additional outputs related to this review, including a shorter brief and an infographic are also available on the SSHAP website.

ii 'Deprivation' or 'deprived people' in this case and in most sources cited by this brief generally refers to those living in the most deprived neighbourhoods in England as measured by the Index of Multiple Deprivation (IMD), an official measure which takes into account income, employment, education, skills and training, health and disability, crime, barriers to housing services, and living environment.

iii 'Ealing has had a higher proportion of people in high-risk 'elementary occupations' roles than London, and also historically, the UK. These include lowpaid roles in areas such as construction or cleaning. The borough is also home to a much larger proportion of processing plant and machine operatives than London and the UK, another group which faced disproportionate risk of death from COVID-19.

iv To be more specific, studies have reported both black African and black Caribbean groups to have the highest hesitancy and lowest uptake. Among South Asian groups, the highest hesitancy and lowest uptake has been reported among people from Pakistani backgrounds, followed by Bangladeshi and Indian groups, all of which have had lower uptake than white British groups ${ }^{26}$ In NWL however, Indian groups have had relatively high uptake.

${ }^{\vee}$ This study did not further disaggregate ethnic groups beyond these categories. Figure 1 offers additional specificity, reflecting considerable differences in uptake between different Asian, black and white groups.

${ }^{v i}$ Figure 1 reflects uptake by JCVI (Joint Committee on Vaccination and Immunisation) cohorts 1-9 which includes all those aged 50 and up, as well as all clinically extremely vulnerable, and at-risk groups in the UK.

vii Figure 2 reflects JCVI cohorts 1-4: all those aged 70+, and clinically extremely vulnerable of all ages.

viii While the term Black, Asian and Minority Ethnic (BAME) is used in official statistics in the UK, it has been critiqued for making differences of ethnicity, religion, class, gender and other aspects of identity and background invisible. Different social and ethnic groups have different experiences and histories and thus, may relate to COVID-19 vaccination programmes differently.

${ }^{\text {ix }}$ The figures for people 18 and over were $74 \%$ with one dose and $70 \%$ with two doses.

${ }^{x}$ While the individual who mentioned this did not specifically indicate what Pfizer trials were implied, and the community members from whom they heard this may not have been more specific than this themselves, it may be safe to assume the memory in question was that of trials for a meningitis drug in northern Nigeria which killed 15 children in 1990s..$^{99}$

\section{REFERENCES}

1. Bear, L., James, D., Simpson, N., Alexander, E., Bazambanza, C., Bhogal, J. K., Bowers, R., Cannell, F., Lohiya, A., Koch, I., Lenhard, J., Long, N. J., Pearson, A., Samanani, F., Vicol, O., Vieira, J., Watt, C., Wuerth, M., Whittle, C., \& Zidaru-Barbulescu, T. (2020). A right to care: The social foundations of recovery from Covid-19 [Monograph]. London School of Economics and Political Science. https://www.Ise.ac.uk/anthropology

2. Baraniuk, C. (2021). Covid-19: How the UK vaccine rollout delivered success, so far. BMJ, 372, n421. https://doi.org/10.1136/bmj.n421

3. Landler, M., \& Mueller, B. (2021, January 29). Vaccine Rollout Gives U.K. a Rare Win in the Pandemic. The New York Times. https://www.nytimes.com/2021/01/29/world/europe/covid-vaccine-uk.html

4. UK Government. (n.d.). Deaths in the UK | Coronavirus in the UK. Retrieved 1 October 2021, from https://coronavirus.data.gov.uk/details/deaths

5. Ham, C. (2021). The UK's poor record on covid-19 is a failure of policy learning. BMJ, 372, n284. https://doi.org/10.1136/bmj.n284

6. Paton, C. (n.d.). 'We did everything we could': An account of toxic leadership. The International Journal of Health Planning and Management, n/a(n/a). https://doi.org/10.1002/hpm.3264

7. Stewart, H. (2021, May 26). UK government failed public on Covid response, says Dominic Cummings. The Guardian. http://www.theguardian.com/politics/2021/may/26/uk-government-failed-public-on-covid-response-says-dominic-cummings

8. West-Oram, P. (2021). Solidarity is for other people: Identifying derelictions of solidarity in responses to COVID-19. Journal of Medical Ethics, 47(2), 65-68.

9. Yamey, G., \& Wenham, C. (2020, July 1). The U.S. and U.K. Were the Two Best Prepared Nations to Tackle a Pandemic-What Went Wrong? Time. https://time.com/5861697/us-uk-failed-coronavirus-response/

10. Science and Technology Committee, \& Health and Social Care Committee. (2021). Coronavirus: Lessons learned to date. https://committees.parliament.uk/work/657/coronavirus-lessons-learnt/news/157991/coronavirus-lessons-learned-to-date-report-published/

11. Ealing Covid-19 Dashboard. (2021).

https://app.powerbi.com/view?r=eyJljoiN2E2ZTVkNjQtYzQ0Yy00MWMzLTgyNTQtNWRhMDJhYjNhOTVIliwidCI6ljAxM2E4YzQzLTgyODctNGM4Yi 04NzhiLTEzMWUzMGNkYjImMylsImMiOjh9\&pageName=ReportSection5e3167bd736ca021bc5a

12. PHE. (2020). Beyond the Data: Understanding the Impact of COVID-19 on BAME Communities (p. 69).

13. Kontopantelis, E., Mamas, M. A., Webb, R. T., Castro, A., Rutter, M. K., Gale, C. P., Ashcroft, D. M., Pierce, M., Abel, K. M., Price, G., Faivre-Finn, C., Spall, H. G. C. V., Graham, M. M., Morciano, M., Martin, G. P., \& Doran, T. (2021). Excess deaths from COVID-19 and other causes by region, neighbourhood deprivation level and place of death during the first 30 weeks of the pandemic in England and Wales: A retrospective registry study. The Lancet Regional Health - Europe, 0(0). https://doi.org/10.1016/j.lanepe.2021.100144

14. London Assembly Health Committee. (2020). Pathways to healthcare: GP experience, COVID-19 and BAME Londoners (p. 22).

15. ONS. (2021). Updating ethnic contrasts in deaths involving the coronavirus (COVID-19), England: 24 January 2020 to 31 March 2021. Office for National Statistics (ONS).

https://www.ons.gov.uk/peoplepopulationandcommunity/birthsdeathsandmarriages/deaths/articles/updatingethniccontrastsindeathsinvolvingthecoro naviruscovid19englandandwales/24january2020to31 march2021\#difference-between-the-risk-of-death-involving-covid-19-by-ethnic-group-in-thefirst-and-second-waves-of-the-pandemic

16. Scientific Advisory Group for Emergencies (SAGE). (2021). Interpreting differential health outcomes among minority ethnic groups in wave 1 and 2. https://www.gov.uk/government/publications/covid-19-ethnicity-subgroup-interpreting-differential-health-outcomes-among-minority-ethnic-groups-inwave-1-and-2-24-march-2021

17. Women and Equalities Committee. (2020). Unequal impact? Coronavirus and BAME people. House of Commons. https://publications.parliament.uk/pa/cm5801/cmselect/cmwomeq/384/38402.htm

18. ONS. (n.d.). Employment by Occupation-Time Series. Nomis - Official Labour Market Statistics. Retrieved 7 October 2021, from https://www.nomisweb.co.uk/reports/lmp/la/1946157266/subreports/empocc_time_series/report.aspx?

19. ONS. (2021). Coronavirus (COVID-19) related deaths by occupation, England and Wales: Deaths registered between 9 March and 28 December 2020.

https://www.ons.gov.uk/peoplepopulationandcommunity/healthandsocialcare/causesofdeath/bulletins/coronaviruscovid19relateddeathsbyoccupation englandandwales/deathsregisteredbetween9marchand28december2020 
20. Public Health England. (2020). Disparities in the risk and outcomes of COVID-19 (p. 92).

21. PHE. (n.d.). Overcrowded households-Ealing. Public Health England. Retrieved 10 June 2021, from https://fingertips.phe.org.uk/search/overcrowding\#page/4/gid/1/pat/6/ati/101/are/E09000009/iid/90416/age/-1/sex/4/cid/4/tbm/1

22. McCullough, N. (2020). How might coronavirus impact the West London economy? (p. 129).

23. CDC. (2021, November 2). Vaccine equity for racial and ethnic minority groups. Centers for Disease Control and Prevention. https://www.cdc.gov/coronavirus/2019-ncov/community/health-equity/vaccine-equity.html

24. WHO. (n.d.). Increasing Vaccination Model. Retrieved 14 July 2021, from https://www.who.int/immunization/programmes systems/Increasing Vaccination Model-WHO.PDF?ua=1

25. MacDonald, N. E., \& the SAGE Working Group on Vaccine Hesitancy. (2015). Vaccine hesitancy: Definition, scope and determinants. Vaccine, 33(34), 4161-4164. https://doi.org/10.1016/j.vaccine.2015.04.036

26. Kamal, A., Hodson, A., \& Pearce, J. M. (2021). A Rapid Systematic Review of Factors Influencing COVID-19 Vaccination Uptake in Minority Ethnic Groups in the UK. Vaccines, 9(10), 1121. https://doi.org/10.3390/vaccines9101121

27. Curtis, H. J., Inglesby, P., MacKenna, B., Croker, R., Hulme, W., Rentsch, C. T., Bhaskaran, K., Walker, A. J., Morton, C. E., Evans, D., Mehrkar, A., Bacon, S., Bates, C., Hickman, G., Ward, T., Morley, J., Cockburn, J., Davy, S., Schultze, A., ... Goldacre, B. (2021). Recording of "COVID-19 vaccine declined" among vaccination priority groups: A cohort study on 57.9 million NHS patients' primary care records in situ using OpenSAFELY (p. 2021.08.05.21259863). https://doi.org/10.1101/2021.08.05.21259863

28. ONS. (2021). Coronavirus and vaccine hesitancy, Great Britain: 31 March to 25 April 2021

https://www.ons.gov.uk/peoplepopulationandcommunity/healthandsocialcare/healthandwellbeing/bulletins/coronavirusandvaccinehesitancygreatbrit ain/31marchto25april

29. Sturgis, P., Macmillan, L., Anders, J., \& Wyness, G. (2021, March 17). Almost two-thirds of Black British young people would be reluctant to get a COVID vaccine. LSE COVID-19. https://blogs.Ise.ac.uk/covid19/2021/03/17/almost-two-thirds-of-black-british-young-people-would-be-reluctant-toget-a-covid-vaccine/

30. Razai, M. S., Osama, T., McKechnie, D. G. J., \& Majeed, A. (2021). Covid-19 vaccine hesitancy among ethnic minority groups. BMJ, 372 , n513. https://doi.org/10.1136/bmj.n513

31. Glampson, B., Brittain, J., Kaura, A., Mulla, A., Mercuri, L., Brett, S., Aylin, P., Sandall, T., Goodman, I., Redhead, J., Saravanakumar, K., \& Mayer, E. K. (2021). North West London Covid-19 Vaccination Programme: Real-world evidence for Vaccine uptake and effectiveness. MedRxiv, 2021.04.08.21254580. https://doi.org/10.1101/2021.04.08.21254580

32. Byrne, T., Patel, P., Shrotri, M., Beale, S., Michie, S., Butt, J., Hawkins, N., Hardelid, P., Rodger, A., Aryee, A., Braithwaite, I., Fong, W. L. E., Fragaszy, E., Geismar, C., Kovar, J., Navaratnam, A. M. D., Nguyen, V., Hayward, A., \& Aldridge, R. W. (2021). Trends, patterns and psychological influences on COVID-19 vaccination intention: Findings from a large prospective community cohort study in England and Wales (Virus Watch) [Preprint]. Public and Global Health. https://doi.org/10.1101/2021.03.22.21254130

33. Phillimore, J. (2011). Approaches to health provision in the age of super-diversity: Accessing the NHS in Britain's most diverse city. Critical Social Policy, 31(1), 5-29. https://doi.org/10.1177/0261018310385437

34. GLA Intelligence. (2012). 2011 Census Snapshot: Ethnic Diversity Indices. Greater London Authority. https://londondatastoreupload.s3.amazonaws.com/gNl\%3D2011-census-snapshot-ethnic-diversity-indices.pdf

35. Ealing Council. (2020). Equalities Needs Assessment (UK). Ealing 1.12 WISP Migration. https://www.ealing.gov.uk/downloads/download/2043/equalities_needs_assessment

36. Trust for London, \& WPI Economics. (2020). London Poverty Profile 2020. https://trustforlondon.fra1.cdn.digitaloceanspaces.com/media/documents/Londons_Poverty_Profile_2020.pdf

37. Chaudhary, V. (2018, April 4). How London's Southall became 'Little Punjab'. The Guardian. http://www.theguardian.com/cities/2018/apr/04/howlondon-southall-became-little-punjab-

38. Baumann, G. (1996). Contesting Culture: Discourses of Identity in Multi-ethnic London. Cambridge University Press.

39. Hamilton, O. (2021, March 13). Poles apart: Why the Polish community doesn't want the vaccine | The Spectator. https://www.spectator.co.uk/article/poles-apart-why-the-polish-community-doesnt-want-the-vaccine

40. Yeo, C. (2018, May 1). Briefing: What is the hostile environment, where does it come from, who does it affect? Free Movement. https://www.freemovement.org.uk/briefing-what-is-the-hostile-environment-where-does-it-come-from-who-does-it-affect/

41. Shahvisi, A. (2019). Austerity or Xenophobia? The Causes and Costs of the "Hostile Environment" in the NHS. Health Care Analysis, 27(3), 202219. https://doi.org/10.1007/s10728-019-00374-w

42. Bradley, G. M. (2018). Care Don't share: Hostile environment data-sharing-Why we need a firewall between essential public services and immigration enforcement. Liberty. https://www.libertyhumanrights.org.uk/issue/care-dont-share/

43. Papageorgiou, V., Wharton-Smith, A., Campos-Matos, I., \& Ward, H. (2020). Patient data-sharing for immigration enforcement: A qualitative study of healthcare providers in England. BMJ Open, 10(2), e033202. https://doi.org/10.1136/bmjopen-2019-033202

44. Doctors of the World. (2017). Deterrence, delay and distress: The impact of charging in NHS hospitals on migrants in vulnerable circumstances [Research Briefing]. Doctors of the World. http://www.doctorsoftheworld.org.uk/wp-content/uploads/import-from-oldsite/files/Research_brief_KCL_upfront_charging_research_2310.pdf

45. MedAct, Migrants Organise, \& New Economics Foundation. (2020). Patients not passports: Migrants' access to healthcare during the coronavirus crisis. https://www.medact.org/wp-content/uploads/2020/06/Patients-Not-Passports-Migrants-Access-to-Healthcare-During-the-CoronavirusCrisis.pdf

46. Imkaan. (2020). The Impact of the Dual Pandemics: Violence Against Women and Girls and COVID-19 on Black and Minoritised Women and Girls [Position paper]. https://rapecrisis.org.uk/media/2253/dual-pandemics-imkaan-report.pdf

47. Wardle, H., \& Obermuller, L. (2019). "Windrush Generation" and "Hostile Environment": Symbols and Lived Experiences in Caribbean Migration to the UK. Migration and Society, 2(1), 81-89. https://doi.org/10.3167/arms.2019.020108

48. Wahlström, Å. M. C. (2009). Friends, Corporate Parents and Pentecostal Churches: Unaccompanied Asylum Seekers from the Democratic Republic of Congo in London [Brunel University]. https://bura.brunel.ac.uk/bitstream/2438/4507/5/FulltextThesis.pdf.txt

49. Enria, L., Waterlow, N., Rogers, N. T., Brindle, H., Lal, S., Eggo, R. M., Lees, S., \& Roberts, C. h. (2021). Trust and transparency in times of crisis: Results from an online survey during the first wave (April 2020) of the COVID-19 epidemic in the UK. PLOS ONE, 16(2), e0239247. https://doi.org/10.1371/journal.pone.0239247

50. Chasma, F., \& Khonat, Z. (2021). How equal is access to senior management and leadership roles in the NHS? British Journal of Healthcare Management, 27(9), 244-247. https://doi.org/10.12968/bjhc.2021.0057

51. Chisnall, G., \& Vindrola-Padros, C. (2021). A rapid literature review on inequalities and ethnicity in healthcare workers' experiences of delivering care during the COVID-19 pandemic. OSF Preprints. https://doi.org/10.31219/osf.io/qri9t

52. Scuzzarello, S. (2015). Narratives and Social Identity Formation Among Somalis and Post-Enlargement Poles: Narratives and Identity among Somalis and Poles. Political Psychology, 36(2), 181-198. https://doi.org/10.1111/pops.12071

53. Bebber, B. (2015). "We Were Just Unwanted": Bussing, Migrant Dispersal, and South Asians in London. Journal of Social History, 48(3), 635-661. https://doi.org/10.1093/jsh/shu110

54. Hossein-Pour, A. (2020, June 18). Ealing Council accused of ignoring BAME residents over 'mounting cancer cases'. MyLondon. https://www.mylondon.news/news/west-london-news/we-cant-breathe-southall-waterside-18446411

55. Diriye, S. (2020). The Impact of COVID-19 on Ealing's BAME Communities. GOSAD. https://www.gosad.org.uk/sites/gosad.hocext.co.uk/files/202009/THE\%20IMPACT\%20OF\%20COVID-19\%200N\%20EALING\%27S\%20BAME\%20COMMUNITIES.pdf 
56. Siddiqui, H., \& Patel, M. (2010). Asian Minority women, domestic violence and mental health: The experience of Southall Black Sisters. In C. Itzin, A. Taket, \& S. Barter-Godfrey, Domestic and Sexual Violence and Abuse: Tackling the Health and Mental Health Effects. Taylor \& Francis Group. http://ebookcentral.proquest.com/lib/suss/detail.action?doclD=592912

57. Marmot, M. (2020). Health equity in England: The Marmot review 10 years on. Bmj, 368.

58. Razai, M. S., Kankam, H. K. N., Majeed, A., Esmail, A., \& Williams, D. R. (2021). Mitigating ethnic disparities in covid-19 and beyond. BMJ, 372 , m4921. https://doi.org/10.1136/bmj.m4921

59. Raleigh, V., \& Holmes, J. (2021). The health of people from ethnic minority groups in England. https://www.kingsfund.org.uk/publications/healthpeople-ethnic-minority-groups-england

60. Knight, M., Bunch, K., Tuffnell, D., Jayakody, H., Shakespeare, J., Kotnis, R., Kenyon, S., \& Kurinczuk, J. (2017). Saving Lives, Improving Mothers' Care-Lessons learned to inform maternity care from the UK and Ireland Confidential Enquiries into Maternal Deaths and Morbidity $2014-16$. University of Oxford: Oxford: National Perinatal Epidemiology Unit.

61. Raisi-Estabragh, Z., McCracken, C., Bethell, M. S., Cooper, J., Cooper, C., Caulfield, M. J., Munroe, P. B., Harvey, N. C., \& Petersen, S. E. (2020). Greater risk of severe COVID-19 in Black, Asian and Minority Ethnic populations is not explained by cardiometabolic, socioeconomic or behavioural factors, or by 25(OH)-vitamin D status: Study of 1326 cases from the UK Biobank. Journal of Public Health (Oxford, England), 42(3), 451-460. https://doi.org/10.1093/pubmed/fdaa095

62. Bradby, H., Lindenmeyer, A., Phillimore, J., Padilla, B., \& Brand, T. (2020). 'If there were doctors who could understand our problems, I would already be better': Dissatisfactory health care and marginalisation in superdiverse neighbourhoods. Sociology of Health \& IIIness, 42(4), 739-757. https://doi.org/10.1111/1467-9566.13061

63. Patel, D., Baker, H., \& Murdoch, I. (2006). Barriers to uptake of eye care services by the Indian population living in Health Education Journal, 65(3), 267-276. https://doi.org/10.1177/0017896906067777

64. Samkange-Zeeb, F., Borisova, L., Padilla, B., Bradby, H., Phillimore, J., Zeeb, H., \& Brand, T. (2020). Superdiversity, migration and use of internetbased health information - results of a cross-sectional survey conducted in 4 European countries. BMC Public Health, 20(1), 1263. https://doi.org/10.1186/s12889-020-09329-6

65. Humphris, R., Bradby, H., Padilla, B., Phillimore, J., Pemberton, S., \& Samerski, S. (2020). After encounters: Revealing patients' unseen work through their pathways to care. International Journal of Migration, Health and Social Care. https://doi.org/10.1108/IJMHSC-07-2019-0066

66. Pemberton, S., Phillimore, J., Bradby, H., Padilla, B., Lopes, J., Samerski, S., \& Humphris, R. (2019). Access to healthcare in superdiverse neighbourhoods. Health and Place, 55, 128-135. https://doi.org/10.1016/j.healthplace.2018.12.003

67. Fairhead, James., \& Leach, M. (2007). Vaccine Anxieties: Global Science Child Health and Society. Science in Society Series. Earthscan; /z-wcorg/. http://www.myilibrary.com?id=110520

68. Bell, S., Edelstein, M., Zatoński, M., Ramsay, M., \& Mounier-Jack, S. (2019). 'I don't think anybody explained to me how it works': Qualitative study exploring vaccination and primary health service access and uptake amongst Polish and Romanian communities in England. BMJ Open, 9(7), e028228. https://doi.org/10.1136/bmjopen-2018-028228

69. Booth, R. (2016, November 15). More than 7m Britons now in precarious employment. The Guardian. http://www.theguardian.com/uknews/2016/nov/15/more-than-7m-britons-in-precarious-employment

70. Pickett, K., \& Wilkinson, R. (2010). The Spirit Level: Why Equality is Better for Everyone. Penguin UK.

71. Trade Unions Congress. (2017). Insecure work and ethnicity. https://www.tuc.org.uk/sites/default/files/Insecure\%20work\%20and\%20ethnicity_0.pdf

72. ONS. (2021). Coronavirus and changing young people's labour market outcomes in the UK - Office for National Statistics. https://www.ons.gov.uk/employmentandlabourmarket/peopleinwork/employmentandemployeetypes/articles/labourmarketeconomicanalysisquarterly/ march2021\#the-distribution-of-young-people-across-industries-changed-during-the-pandemic

73. Yordanova, I. (2021). A detailed study of unemployment in London. Volterra Partners LLP for London Councils. https://www.londoncouncils.gov.uk/our-key-themes/economic-development/employment-support/detailed-study-unemployment-london

74. Stuckler, D., Reeves, A., Loopstra, R., Karanikolos, M., \& McKee, M. (2017). Austerity and health: The impact in the UK and Europe. European Journal of Public Health, 27(suppl_4), 18-21. https://doi.org/10.1093/eurpub/ckx167

75. London Councils. (2018). London's local services: Investing in the future | London Councils. London Councils. https://www.londoncouncils.gov.uk/our-key-themes/local-government-finance/london\%E2\%80\%99s-local-services-investingfuture/london\%E2\%80\%99s-local

76. Sanders-McDonagh, E., Neville, L., \& Nolas, S.-M. (2016). From Pillar to Post: Understanding the Victimisation of Women and Children who Experience Domestic Violence in an Age of Austerity. Feminist Review, 112(1), 60-76. https://doi.org/10.1057/fr.2015.51

77. Special Issue Editors: Birgit Glorius and Jeroen Doomernik, \& Darling, J. (2016). Asylum in Austere Times: Instability, Privatization and Experimentation within the UK Asylum Dispersal System. Journal of Refugee Studies, 29(4), 483-505. https://doi.org/10.1093/jrs/few038

78. Loopstra, R., Reeves, A., Barr, B., Taylor-Robinson, D., \& Stuckler, D. (2014). Are austerity measures in England driving rises in homelessness? Evidence from 324 Local Authorities 2004-2012: Rachel Loopstra. European Journal of Public Health, 24(suppl_2). https://doi.org/10.1093/eurpub/cku166.082

79. Berg, M. L. (2019). Super-diversity, austerity, and the production of precarity: Latin Americans in London. Critical Social Policy, 39(2), 184-204 https://doi.org/10.1177/0261018318790744

80. Ealing Council. (2012). State of Ealing Economy and Enterprise.

81. ONS. (2021). Labour Market Profile-Ealing [Nomis Official Labour Statistics]. ONS. https://www.nomisweb.co.uk/reports/Imp/la/1946157266/report.aspx\#tabempocc

82. SQW. (2016). Park Royal workforce skills (p. 55). https://www.london.gov.uk/sites/default/files/park_royal_workforce_skills_final_report-june2016.pdf

83. Stewart, R., \& Ahlawat, R. (2015). Deprivation in Ealing. A Report on the English Indices of Deprivation 2015. Ealing Council. https://www.ealing.gov.uk/downloads/download/1015/indices_of_deprivation_for_ealing

84. Trust for London. (2021). Poverty \& Inequality Data Ealing. Trust for London. https://www.trustforlondon.org.uk/data/boroughs/ealing-poverty-andinequality-indicators/

85. Mangara, M. (2017). Ealing JSNA 2017: Population characteristics. Ealing Council. https://data.ealing.gov.uk/wp-content/uploads/Populationcharacteristics-JSNA-2017.pdf

86. ONS. (2020). Employment Rates by Ethnicity. https://data.london.gov.uk/dataset/employment-rates-by-ethnicity

87. GMB. (2017). Insecure: Tackling precarious work and the gig economy. https://gmb.org.uk/sites/default/files/GMB17-InsecureWork.pdf

88. ONS. (2020). Greater London Authority- Workers on Zero Hour Contracts. Greater London Authority. https://data.london.gov.uk/dataset/workers-onzero-hours-contracts

89. Skills for Care. (2020). A summary of the adult social care sector and workforce in Ealing 2019/20. Skills for Care. www. skillsforcare.org.uk/adultsocial-care-workforce-data/Workforce-intelligence/publications/Topics/COVID-19A summary of the adult social care sector and workforce in Ealing

90. Vicol, D. O. (2020). Case Study: Work Rights Centre. In Right to Care: The Social Foundations of Recovery from Covid-19. LSE Monograph.

91. Oxford Economics. (2020). How might coronavirus impact the West London economy? Oxford Economics http://democracy.lbhf.gov.uk/documents/s113727/Annex\%20A\%20-

\%20How\%20might\%20coronavirus\%20affect\%20the\%20West\%20London\%20Economy\%200xford\%20Economics.pdf

92. PHE. (2021). COVID-19: Migrant health guide. Public Health England. https://www.gov.uk/guidance/covid-19-migrant-health-guide 
93. Dibb, S. (n.d.). Where the UK government is going wrong in its coronavirus messaging, according to a marketing expert. The Conversation. Retrieved 9 June 2021, from http://theconversation.com/where-the-uk-government-is-going-wrong-in-its-coronavirus-messaging-according-to-amarketing-expert-146783

94. Independent SAGE. (2021). Covid-19: Racialised stigma and inequalities. The Independent SAGE Report 33. The Independent Scientific Advisory Group for Emergencies (SAGE). https://www.independentsage.org/wp-content/uploads/2021/01/Stigma-and-Inequalities_16-12-20_D6.pdf

95. Elvery, M., \& Hossein-Pour, A. (2021, April 6). Southall's legendary anti-racism campaigner slams Government racism report. MyLondon. https://www.mylondon.news/news/west-london-news/london-anti-racism-campaigners-slam-20328509

96. Chikoko, C. (2021, February 11). Comment: Government must go beyond a press release to get undocumented migrants vaccinated. Free Movement. http://www.freemovement.org.uk/comment-government-must-go-beyond-a-press-release-to-get-undocumented-migrants-vaccinated/

97. Joint Council for the Welfare of Immigrants. (2021). Migrants deterred from healthcare during the COVID-19 pandemic. Joint Council for the Welfare of Immigrants. https://www.jcwi.org.uk/migrants-deterred-from-healthcare-in-the-covid19-pandemic

98. UK Government. (2021). UK Coronavirus Dashboard. https://coronavirus.data.gov.uk/details/download

99. Smith, D., \& Africa. (2011, August 12). Pfizer pays out to Nigerian families of meningitis drug trial victims. The Guardian. https://www.theguardian.com/world/2011/aug/11/pfizer-nigeria-meningitis-drug-compensation

100. RSPH. (2020). New poll finds ethnic minority groups less likely to want COVID vaccine. https://www.rsph.org.uk/about-us/news/new-poll-findsbame-groups-less-likely-to-want-covid-vaccine.html

101. Healthwatch. (2021, February). Getting to vaccine centres more of a barrier for Black communities | Healthwatch. https://www.healthwatch.co.uk/news/2021-02-22/getting-vaccine-centres-more-barrier-black-communities

102. UK Government. (2021). Interactive map of vaccinations. Coronavirus in the UK. https://coronavirus.data.gov.uk/details/interactivemap/vaccinations

103. SAGE SPI-B. (2020). The role of Community Champion networks to increase engagement in teh context of COVID-19: Evidence and best practice. https://assets.publishing.service.gov.uk/government/uploads/system/uploads/attachment_data/file/933231/S0830_SPI-B_-

_Community_Champions_evidence_and_best_practice.pdf

\section{ACKNOWLEDGEMENTS}

This review has been written by Tabitha Hrynick (t.hrynick1@ids.ac.uk) and Santiago Ripoll.

We also wish to acknowledge expert input from others. Expert review was provided by: Maddy Gupta-Wright, Public Health team at London Borough of Ealing; Dr Ellen Schwartz, Immunisation lead for the Association of Directors of Public Health in London (ADPHL); Dr Nikita Simpson, London School of Economics; Hayley MacGregor, Institute of Development Studies (IDS) and SSHAP; and Melissa Parker, London School of Hygiene and Tropical Medicine (LSHTM) and SSHAP.

Additional acknowledgements are also extended to: Christopher Jack, Janpal Basran, Angela Dodwell, Paul Najsarek, Vijay Tailor, Steve Curtis, Matt Van Mol-Jones, Tan Afzul, Evelyn Gloyne, Rajiv Ahlawat, Ryan Ashlee, lan Smith, Chrissy Leonard, Gary Redhead, Manpreet Bains, Neha Unadkat, Jack Butler, Cheryl Curling, Anna Bryden and Violet Mendonca.

\section{CONTACT}

If you have a direct request concerning the brief, tools, additional technical expertise or remote analysis, or should you like to be considered for the network of advisers, please contact the Social Science in Humanitarian Action Platform by emailing Annie Lowden (a.lowden@ids.ac.uk) or Olivia Tulloch (oliviatulloch@anthrologica.com).

The Social Science in Humanitarian Action is a partnership between the Institute of Development Studies, Anthrologica and the London School of Hygiene and Tropical Medicine. This work was supported by the UK Foreign, Commonwealth and Development Office and Wellcome Grant Number $219169 / Z / 19 / Z$. The views expressed are those of the authors and do not necessarily reflect those of the funders, or the views or policies of IDS, Anthrologica or LSHTM.
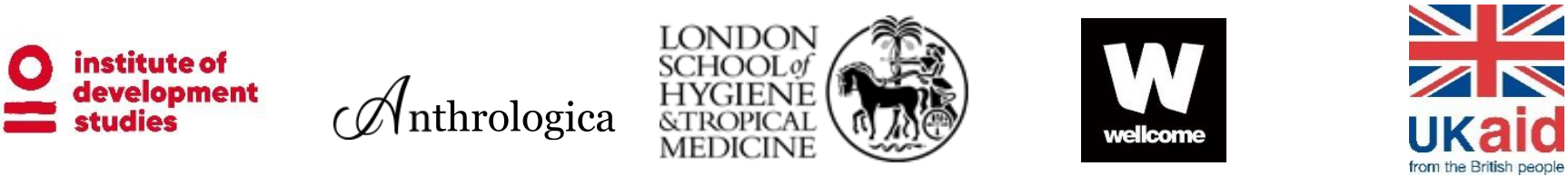

\section{KEEP IN TOUCH}

\section{@SSHAP Action D}

Suggested citation: Hrynick, T. and Ripoll, S. (2021). Evidence Review: Achieving COVID-19 Vaccine Equity in Ealing and North West London. Social Science In Humanitarian Action (SSHAP) DOI: 10.19088/SSHAP.2021.040

https://doi.org/10.19088/SSHAP.2021.040

Published November 2021

(C) Institute of Development Studies 2021

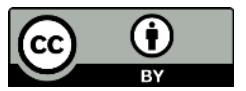

This is an Open Access paper distributed under the terms of the Creative Commons Attribution 4.0 International licence (CC BY), which permits unrestricted use, distribution, and reproduction in any medium, provided the original authors and source are credited and any modifications or adaptations are indicated. http://creativecommons.org/licenses/by/4.0/legalcode 